PRODUCTION

ENGINEERING ARCHIVES
2015, Vol. 6, No 1, pp 2-5

ISSN 2353-5156

ISSN 2353-7779 (print version)

(online version)

\title{
Morphology of intermetallic phases in Al-Si cast alloys and their fracture behaviour
}

\author{
Lenka Hurtalová $^{1}$, Eva Tillová ${ }^{1}$, Mária Chalupová ${ }^{1}$, Juraj Belan ${ }^{1}$ \\ ${ }^{1}$ University of Žilina, Faculty of Mechanical Engineering, Department of Materials Engineering, Univerzitná 8215/1, 010 26 Žilina, Slo- \\ vakia, phone: 00421/415132626, e-mail: lenka.hurtalova\{eva.tillova, maria.chalupova, juraj.belan\}@fstroj.uniza.sk

\begin{abstract}
Applications of Al-Si cast alloys in recent years have increased especially in the automotive industry (dynamic exposed cast, engine parts, cylinder heads, pistons and so on). Controlling the microstructure of secondary aluminium cast alloys is very important, because these alloys contain more additional elements that form various intermetallic phases in the structure. Therefore, the contribution is dealing with the valuation type of intermetallic phases and their identification with using optical and scanning microscopy. Some of the intermetallic minium alloy are affected by morphology of intermetallic phases and therefore it is necessary to study morphology and its fracture behaviour. The present work shows morphology and typical fracture behaviour as the most common intermetallic phases forming in Al-Si alloys.
\end{abstract} \\ phases could be identified on the basis of morphology but some of them must be identified according EDX analysis. The properties of alu-
}

Key words - morphology of intermetallic phases, Al-Si alloys, fracture behaviour of intermetallic phases

\section{Introduction}

Aluminium alloys have been the most common materials in different industries, but especially in the areas of aerospace and automotive, on account of their high stiffness/weight ratio and strength/weight ratio, good formability, good corrosion resistance etc. (XING M. Z., 2013; MilleR W. S., 2000; MATVIJA M., 2012, ULEWICZ, R., 2014).

The final microstructure of aluminium material determines the technological and mechanical properties of cast components. Mechanical properties can be affected by casting method, solidification rate, heat treatment or modifying and grain refining (FARAHANYA S., 2013; TIMPEL M., 2012; XIUFANG B., 2001).

Al-Si-Cu alloys usually contain $\mathrm{Cu}(2-4 \%)$, a certain amount of $\mathrm{Fe}, \mathrm{Mn}, \mathrm{Mg}$ and $\mathrm{Zn}$ that are pre- sent either unintentionally, or they are added deliberately to provide special material properties. These elements partly go into solid solution in the matrix and partly form intermetallic particles during solidification (RIOS C.T., 2003). The influence of intermetallic phases to mechanical and fatigue properties depends on size, volume and morphology of these phases (Tillová E., 2010). The formation of these phases should correspond to successive reactions during solidification with an increasing number of phases involved at a decreasing temperature. In practice, Bäckerud et al. (BÄCKERUD L., 1986; BÄCKERUD L., 1992) identified these reactions in $\mathrm{Al}-\mathrm{Si}-\mathrm{Cu}$ alloy:

- $602^{\circ} \mathrm{C}$ : $\alpha$-dendritic network. The exact temperature depends on the $\mathrm{Si}$ and $\mathrm{Cu}$ concentration in the alloy;

- $590^{\circ} \mathrm{C}$ : Liq. $\rightarrow \alpha$-phase $+\mathrm{Al}_{15}(\mathrm{Fe}, \mathrm{Mn})_{3} \mathrm{Si}_{2}$;

- $575^{\circ} \mathrm{C}-507^{\circ} \mathrm{C}$ : Liq. $\rightarrow \alpha$-phase $+\mathrm{Si}+\mathrm{Al}_{5} \mathrm{FeSi}$; 
- $525^{\circ} \mathrm{C}-507^{\circ} \mathrm{C}$ : Liq. $\rightarrow \alpha$-phase $+\mathrm{Al}_{2} \mathrm{Cu}+\mathrm{Al}_{5} \mathrm{FeSi}$ $+\mathrm{Si}$. Reduction of temperature allows nucleation of Cu-enriched eutectic $\left(\mathrm{Al}+\mathrm{Al}_{2} \mathrm{Cu}\right)$;

- $507^{\circ} \mathrm{C}: \quad$ Liq. $\rightarrow \alpha$-phase $+\mathrm{Al}_{2} \mathrm{Cu}+\mathrm{Si}+$ $\mathrm{Al}_{5} \mathrm{Mg}_{8} \mathrm{Si}_{6} \mathrm{Cu}_{2}$.

- $483^{\circ} \mathrm{C}$ : End of the alloy solidification (solidus temperature).

Suwanpinij et al. (SUWANPINIJ P., 2003) calculated crystallization temperatures of major phases by the Gulliver-Scheil model in the 380-type alloy (Fig. 1).

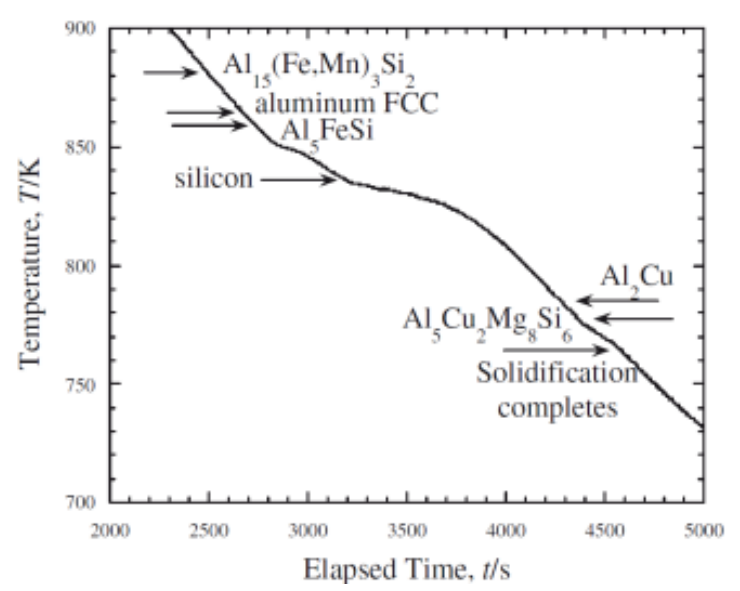

Fig.1 The cooling curve of 380-type alloy (SUWANPINIJ P., 2003)

The present study is a part of a larger research project, which was focused on a study of secondary Al-Si cast alloy. The purpose of the present article is to investigate the microstructure of recycled AlSi9Cu3 cast alloy with a combination different analytical techniques and valuations of fracture behaviour structure components.

\section{Methodology of research}

As an experimental material was used secondary AlSi9Cu3 alloy, that contains $9.4 \% \mathrm{Si}, 2.4 \% \mathrm{Cu}, 0.9$ \% Fe, $0.28 \% \mathrm{Mg}, 0.24 \% \mathrm{Mn}, 1.0 \% \mathrm{Zn}, 0.03 \% \mathrm{Sn}$, $0.09 \% \mathrm{~Pb}, 0.04 \% \mathrm{Ti}, 0.05 \% \mathrm{Ni}, 0.04 \%$ Cr. The secondary alloy (prepared by recycling of aluminium scrap) was received in the form of $12.5 \mathrm{~kg}$ ingots. Experimental material was molten into the metallic mould (chill casting). The melting temperature was maintained at $760{ }^{\circ} \mathrm{C} \pm 5{ }^{\circ} \mathrm{C}$. Molten metal was purified with salt AlCu4B6 before casting and was not modified or grain refined. The microstructure of ex- perimental material was studied using light microscope Neophot 32 and SEM observation with EDX analysis using scanning electron microscope VEGA LMU II linked to the energy dispersive $\mathrm{X}$-ray spectroscopy (EDX analyzer Brucker Quantax). The samples for metallographic observations $(1.5 \mathrm{~cm} \times 1.5 \mathrm{~cm})$ were prepared by standard metallographic procedures (wet ground, polished with diamond pastes, finally polished with commercial fine silica slurry - STRUERS OP-U and etched by standard (Dix-Keller, $0.5 \%$ HF) reagent. Some samples were also in order to reveal the threedimensional morphology of the silicon phase and intermetallic phases deep-etched for $30 \mathrm{~s}$ in $\mathrm{HCl}$ solution. The fracture surface (and fracture behaviour of structure components) was observed by using scanning electron microscope on Charpy impact specimens after impact bending test.

\section{Results and discussions}

According to the theory above, the four main types of intermetallic phases occurring in this AlSiCu alloy are $\mathrm{Al}_{5} \mathrm{FeSi} ; \quad \mathrm{Al}_{15}(\mathrm{Mn}, \mathrm{Fe})_{3} \mathrm{Si}_{2} ; \quad \mathrm{Al}_{2} \mathrm{Cu} ; \quad$ and $\mathrm{Al}_{5} \mathrm{Cu}_{2} \mathrm{Mg}_{8} \mathrm{Si}_{6}$ (RiOs C.T., 2003; TAYLOR J. A., 2004; SEIFEDDINE S., 2007). In experimental recycled AlSi9Cu3 cast alloy that contains less than $0.9 \%$ of Fe and $0.24 \mathrm{Mn}$ it was found:

- $\quad$ very short and little $\mathrm{Al}_{5} \mathrm{FeSi}$ needles (Fig. 2a) - in a small volume;

- long $\mathrm{Al}_{15}(\mathrm{FeMn})_{3} \mathrm{Si}_{2}$ skeleton like (Fig. 2b -red) these phases were dominant from Fe-rich;

- small $\mathrm{Al}_{2} \mathrm{Cu}$ particles (Fig. 3a);

- $\quad$ and eutectic $\mathrm{Al}-\mathrm{Al}_{2} \mathrm{Cu}-\mathrm{Si}$ phases (Fig. 3b).

$\mathrm{Al}_{5} \mathrm{FeSi}$ phases precipitate in the interdendritic and intergranular regions as platelets (appearing as needles in the metallographic microscope). Long and brittle $\mathrm{Al}_{5} \mathrm{FeSi}$ platelets (more than $500 \mu \mathrm{m}$ ) can adversely affect mechanical properties, especially ductility, and also lead to the formation of excessive shrinkage porosity defects in castings (RIOS C.T., 2003; TAYLOR J. A., 2004). The $\beta$ platelets appeared to be the main nucleation sites for the eutectic $\mathrm{Si}$, eutectic $\mathrm{Al}_{2} \mathrm{Cu}$ and $\mathrm{Cu}$-rich phase. Excess $\mathrm{Mn}$ may reduce $\mathrm{Al}_{5} \mathrm{FeSi}$ phase and promote formation Fe-rich phases $\mathrm{Al}_{15}(\mathrm{FeMn})_{3} \mathrm{Si}_{2}$ (known as alpha- or $\alpha$-phase) in the form „skeleton like“ or in the form "Chinese script". Phase $\mathrm{Al}_{15}(\mathrm{FeMn})_{3} \mathrm{Si}_{2}$ is considered less harmful to the me- 
chanical properties than $\beta$ phase (RIOS C.T., 2003; TAYLOR J. A., 2004; SEIFEDDINE S., 2007).

The Cu-rich intermetallic phases observed in experimental material are important when material is heat treated. These phases led to formation $\Theta$ and $\Theta^{\prime}$ precipitates with body centered-tetragonal crystal structure with the stoichiometry $\mathrm{Al}_{2} \mathrm{Cu}$ in substructure and improve mechanical properties of materials (BISWAS A., 2014).

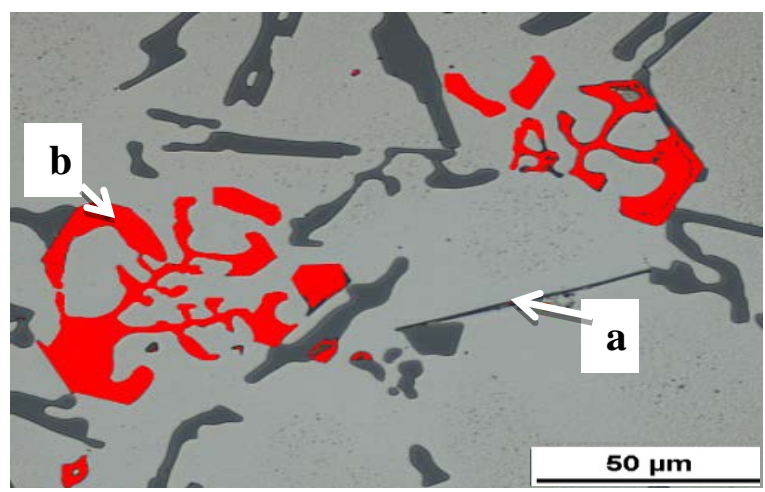

Fig. 2 The morphology of Fe-rich phases, etch. DixKeller

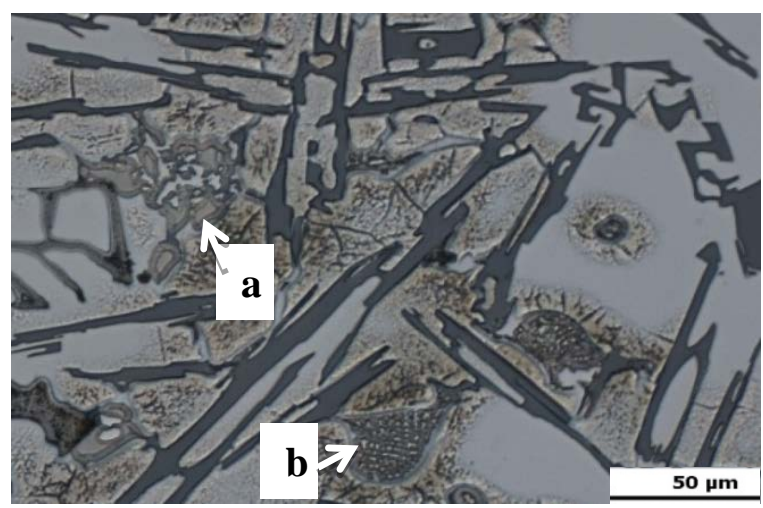

Fig. 3 The morphology of Cu-rich phases, etch. DixKeller

The fracture surface was influenced very significantly by structural components ( $\alpha$-phase, eutectic silicon, intermetallic phases) and their distribution in the cross section. The overall appearance of the fracture surface is not only a violation of the matrix $(\alpha-$ phase), but also the shape and size of eutectic $\mathrm{Si}$ and intermetallic phases.

The matrix is characterized by high plasticity while the crystals of eutectic silicon and Fe-rich intermetallic phases have higher values of hardness and so almost zero values of plastic properties. Therefore, the fracture surface of AlSi9Cu3 cast alloy composed of matrix and $\mathrm{Cu}$-rich intermetallic phases ductile fracture and cleavage fracture of hard and brittle structural components (eutectic $\mathrm{Si}$ and Fe-rich intermetallic phases).

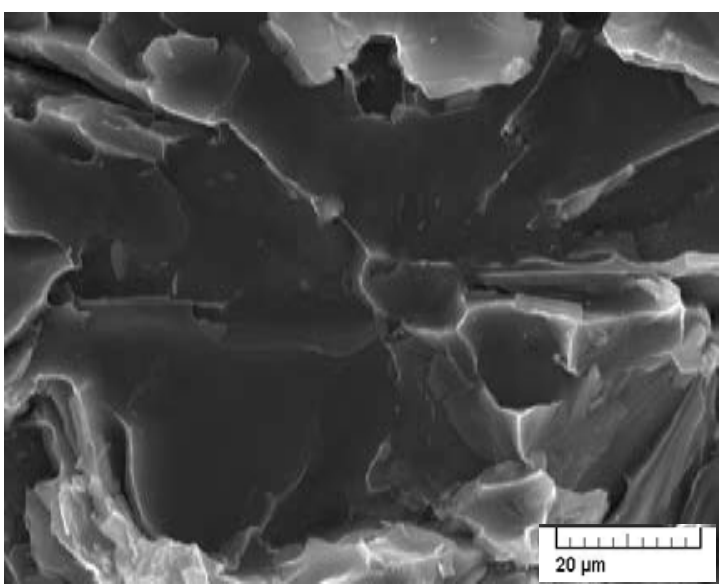

Fig. 4 The fracture of Si particles on the fracture surface

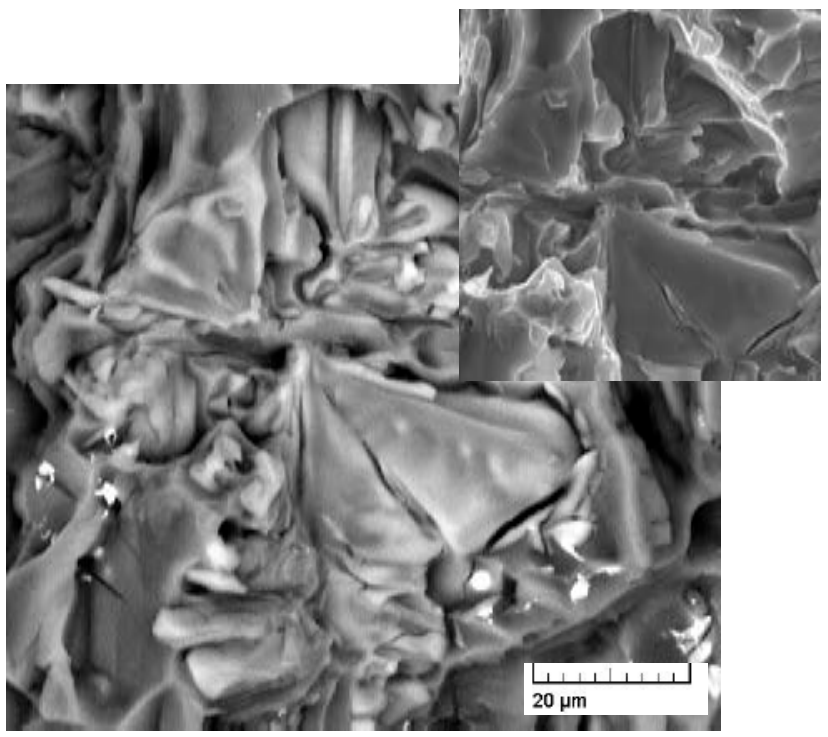

Fig. 5 The fracture of skeleton like Fe-rich phase on the fracture surface

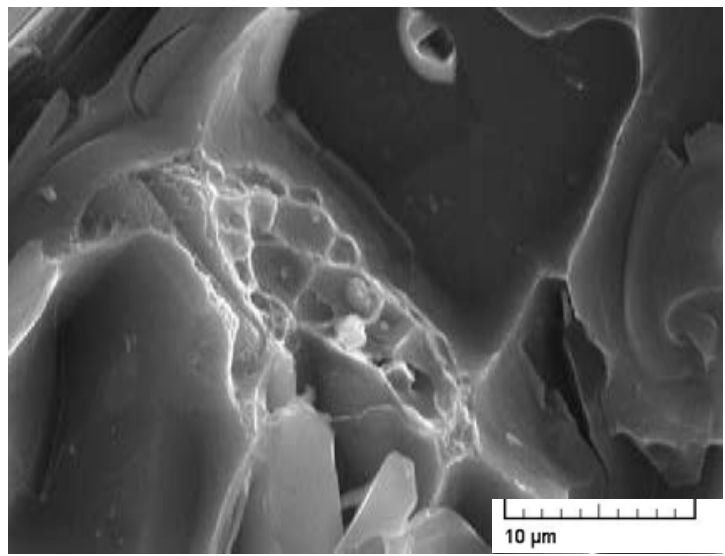

Fig. 6 The fracture of $\mathrm{Al}-\mathrm{Al}_{2} \mathrm{Cu}$-Si $\mathrm{Cu}$-rich phase on the fracture surface 


\section{Summary and conclusions}

In the present study, the morphology and fracture behaviour of intermetallic phases in AlSi9Cu3 cast alloy was investigated. From the analysis of the results the following conclusions can be drawn:

In AlSi9Cu3 cast alloy two Fe-rich phases were observed - $\mathrm{Al}_{5} \mathrm{FeSi}$ needles; skeleton-like $\mathrm{Al}_{15}(\mathrm{FeMn})_{3} \mathrm{Si}_{2}$ and two Cu-rich intermetallic phases $\mathrm{Al}_{2} \mathrm{Cu}$ and $\mathrm{Al}-\mathrm{Al}_{2} \mathrm{Cu}-\mathrm{Si}$.

$\mathrm{Al}_{15}(\mathrm{FeMn})_{3} \mathrm{Si}_{2}$ phase was dominant thanks to the presence of Mn. The morphology and size of iron phases are undesirable.

The morphology of structural components (eutectic silicon, intermetallic Fe-rich and $\mathrm{Cu}$-rich phases) significantly affects the fracture surface of Al-alloy.

The fracture surface of as-cast state is forming of transcrystalline cleavage and ductile fracture. On the fracture surface, transcrystalline cleavage fracture is dominant. Transcrystalline cleavage fracture is related to the presence of large hexagonal plate-Si particles in the structure and also brittle iron intermetallic phases. The transcrystalline ductile fracture of $\mathrm{Al}$ matrix $(\alpha-$ phase) and $\mathrm{Cu}$ rich intermetallic phases is observed in the smaller surface.

\section{Additional information}

This work has been supported by Scientific Grant Agency of Ministry of Education of Slovak republic $\mathrm{N}^{\mathrm{o}} 1 / 0533 / 15, \mathrm{~N}^{\mathrm{0}} 0044 \mathrm{Z} U-4 / 2014$ and EU project ITMS 26220220154.

\section{Literature}

1. BÄCKERUD L., et al. 1986: Solidification Characteristics of Aluminum Alloys, „Universitetsforlaget“, Oslo 1226.

2. BÄCKERUD L., et al. 1992: Solidification Characteristics of Aluminum Alloys, „The American Foundry Society“ 226.

3. BISWA A., et al. 2014: Compositional evolution of

Q-phase precipitates in an aluminum alloy. „Acta Materialia“ 75 322-336

4. CÁCERES C. H., et al. 1999: The effect of Cu content on the level of microporosity in $\mathrm{Al}-\mathrm{Si}-\mathrm{Cu}-\mathrm{Mg}$ casting alloys. „Scripta Materialia” 40/5 631-637

5. FARAHANYA S., et al. 2013: Evaluation of the ef- fect of $\mathrm{Bi}, \mathrm{Sb}, \mathrm{Sr}$ and cooling condition on eutectic phases in an Al-Si-Cu alloy (ADC12) by in situ thermal analysis. „Thermochimica Acta” 55959.

6. Matvija M., et al. 2012: The effect of ecap and subsequent post-ecap annealing on the microstructure and mechanical properties of AlSi7Mg0.3 alloy. „Acta Metallurgica Slovaca” $18 / 14$

7. MiLleR W. S., et al. 2000: Recent development in aluminium alloys for the automotive industry. „Materials Science and Engineering” A 28037

8. XING M., et al. 2013: Dynamic Fracture Behaviors of Selected Aluminum Alloys Under Threepoint Bending. „Defence Technology” 9/4 193200

9. RIOS C.T., et al. 2003: Intermetallic compounds in the Al-Si-Cu systém. „Acta microscopia” 12 77-82

10. SEIFEDDINE S. 2007: The influence of Fe on the microstructure and mechanical properties of cast Al-Si alloys. "Literature review - Vilmer project". Jönköping University Sweden

11. SUWANPINIJ P., et al. 2003: Influence of Copper and Iron on Solidification Characteristics of 356 and 380-Type Aluminum Alloys. „Materials Transactions“ 44/5 845 - 852

12. TAYLOR J. A. 2004: The effect of iron in Al-Si casting alloys. " $35^{\text {th }}$ Australian Foundry Institute National Conference Adelaide South Australia” 148

13. TillovÁ E., et al. 2010: Evolution of the Fe-rich phases in recycled AlSi9Cu3 cast alloy during solution treatment. „Communications - Scientific letters of the university of Žilina” 12/4 95-101

14. TIMPEL M. and et al. 2012: The role of strontium in modifying aluminium-silicon alloys. "Acta Materialia” 603920.

15. TOKAR M., et al. 2014: The effect of strontium and antimony on the mechanical properties of $\mathrm{Al}-\mathrm{Si}$ alloys. „Mateials Science and Engineering“ 39/1 69.

16. UleWICZ, R. 2014: Practical application of quality tools in the cast iron forundry. „Manufacturing technology“ 14/1 104-111

17. XiUfang B., et al. 2001: Liquid structure of Al$12.5 \%$ Si alloy modified by antimony. „Materials Characterization” 46/1 25-29 